\title{
O desengajamento do trabalho artesão e os rumos da nova geração na comunidade do Alto do Moura-PE
}

\author{
Denise Clementino de Souza ${ }^{1}$ \\ JESSICA RANI FERREIRA DE SOUSA ${ }^{1}$ \\ MARCIO GOMES DE SÁ ${ }^{2}$ \\ BÁRBARA TAYNA LEAL ${ }^{1}$
}

${ }^{1}$ Universidade Federal de Pernambuco (UFPE) / Centro Acadêmico do Agreste, Núcleo de Gestão, Caruaru - PE, Brasil

2 Universidade Federal da Paraíba (UFPB) / Departamento de CIÊNCIAS SOCIAIS, JoÃo PeSSOA - PB, BRASIL

\section{Resumo}

Este trabalho teve como principal objetivo analisar as condições e os modos de desengajamento da nova geração da comunidade artesã do Alto do Moura, em Pernambuco. Apoiando-se na sociologia bourdieusiana, propusemo-nos a investigar quais gatilhos estimulam os indivíduos a tomar um ou outro rumo diferente do ofício de artesão, bem como quais as principais demandas disposicionais para mudanças na herança incorporada em sua condição artesã. Os principais gatilhos contextuais identificados como pertinentes ao desengajamento foram referentes à dificuldade de transmissão geracional, ao declínio do valor simbólico e à carência de incentivos do poder público, ao anseio por estabilidade em outras profissões por meio do estudo formal e à dificuldade de geração de renda por meio do artesanato. Os principais rumos analisados foram relativos à transição da condição artesã para um negócio próprio na comunidade, para uma atividade técnico-profissional formal especializada, formal não especializada ou, ainda, para atividade informal intermitente. Por fim, expomos um olhar para o trabalho fora da condição artesã nas considerações finais.

Palavras-chave: Desengajamento. Trabalho artesão. Alto do Moura. Sociologia bourdieusiana. Mudança geracional.

\section{The disengagement of artisan work and the paths of the new generation in the community of Alto do Moura-PE}

\section{Abstract}

This study analyzed the life conditions and the disengagement of the new generation of inhabitants of the community of Alto do Moura, in the Brazilian state of Pernambuco. Based on Bourdieusian sociology, the research examines the elements that influence a younger generation in that community to take a different course from the traditional artisan work. In addition, we observe the disposition demands that lead these youngsters to seek changes in the inherited condition of 'artisan.' The main influential elements identified were the difficulty of generational transmission, the decline in symbolic value, the lack of incentives from the public authorities, the desire for stability in other professions through formal education, and the difficulty of generating income through craftsmanship. As for the new paths observed among the new generation, the study revealed the transition from the condition of 'artisan' to owning a business in the community, to a formal specialized technical-professional activity, formal non-specialized, or an informal intermittent professional activity. The article concludes with a reflection on the work outside the condition of 'artisan'.

Keywords: Disengagement. Artisan Work. Alto do Moura. Bourdieusian sociology. Generational change.

\section{La desvinculación del trabajo artesanal y los rumbos de la nueva generación en la comunidad de Alto do Moura, PE}

\section{Resumen}

Este trabajo tuvo como objetivo principal analizar las condiciones y los modos de desvinculación de la nueva generación de la comunidad artesanal de Alto do Moura, en Pernambuco. Apoyándonos en la sociología bourdieusiana, nos propusimos investigar qué factores desencadenantes estimulan a los individuos a tomar un u otro rumbo diferente del oficio de artesano, así como cuáles son las principales demandas disposicionales para los cambios en la herencia incorporada a su condición artesanal. Los principales factores desencadenantes contextuales identificados como pertinentes a la desvinculación se relacionaron con la dificultad de la transmisión generacional, la disminución del valor simbólico, la falta de incentivos del poder público, el deseo de estabilidad en otras profesiones a través del estudio formal y la dificultad de generación de ingresos mediante la artesanía. Los principales rumbos analizados están relacionados con la transición de la condición artesanal a un negocio propio en la comunidad, a una actividad técnico-profesional formal especializada, formal no especializada o, aún, a una actividad informal intermitente. Por último, exponemos una observación del trabajo fuera de la condición artesanal en las consideraciones finales.

Palabras clave: Desvinculación. Trabajo artesanal. Alto do Moura. Sociología bourdieusiana. Cambio generacional. 


\section{INTRODUÇÃO}

A atividade artesã é normalmente transmitida de geração para geração e reproduzida no modo de vida, nos saberes e nos fazeres de determinada sociedade. É considerada uma atividade social devido ao modo como se organiza - as gerações mais novas são iniciadas ainda na infância como forma de complementar o sustento da família (ARAÚJO, 2006; LOPEZ e BIZUET, 2019). Em pleno século XXI, ainda é possível encontrar no Brasil e mundo afora comunidades que se constituíram ou se desenvolveram em função de uma atividade artesanal que lhes conferiu identidade (senso de pertencimento) e sustento (CANCLINI, 1983; ARAÚJO, 2006; BEZERRA, 2007; ALVARADO, CUENTAS e FERNÁNDEZ, 2016; SÁ, SOUSA, SOUZA et al., 2018).

Segundo um estudo realizado pelo Ministério do Desenvolvimento, Indústria e Comércio (MDIC), só em 2010 a atividade movimentou uma média de $\mathrm{R} \$ 28$ bilhões, representando cerca de $3 \%$ do Produto Interno Bruto (PIB) nacional. No início desta década, o país possuía aproximadamente 8,5 milhões de artesãos (BRASIL, 2013).

O Programa do Artesanato Brasileiro (PAB) entende artesanato como trabalho decorrente do uso de matérias-primas, feito manualmente por uma pessoa que detenha técnicas, criatividade, habilidade e valor cultural, e busca fortalecê-lo como forma de geração de renda e viabilizar o acesso para novos mercados, a partir da capacitação dos artesãos (BRASIL, 2010b).

No âmbito internacional da literatura, o artesanato ainda é apontado como uma fonte relevante de ocupação. Na União Europeia, é tido como essencial para a prosperidade e o bem-estar das pessoas (DRAGIN, KRUSMETRA, JEROSCENKOVA et al., 2015); na África do Sul, corrobora-se sua importância para a diminuição da pobreza (MAKHITHA, 2016); e na América Latina faz parte do cotidiano de muitos como um meio de subsistência integrado à sua relevância cultural (ALVARADO, CUENTAS e FERNÁNDEZ, 2016), que contribui para o desenvolvimento regional (SÁNCHEZ-MEDINA, 2018).

No âmbito nacional, pesquisas anteriores já apontam indícios capazes de conduzir e justificar uma problematização e preocupação com a continuidade da atividade artesã na contemporaneidade, dadas suas semelhanças a modelos produtivos "pré-capitalistas" (FIGUEIREDO e MARQUESAN, 2014; FIGUEIREDO, MELO, MATOS et al., 2015), ou ainda por atentar para as implicações e o significado de intervenções governamentais ou do terceiro setor no fomento à atividade (BEZERRA, 2007; MARQUESAN e FIGUEIREDO, 2014; KELLER, 2015).

Em Caruaru, no agreste pernambucano, a produção e o comércio de artesanato em barro do Alto do Moura representam a principal fonte de renda para os membros da comunidade que parilham o ofício geração após geração (IPHAN, 2006). Situado a $7 \mathrm{~km}$ do centro da cidade, o bairro ganhou reconhecimento nacional devido à produção figurativa que costumava representar cenas do cotidiano do interior nordestino (os retirantes, o vaqueiro etc.), seguindo a trilha aberta por Mestre Vitalino (19091963) (SILVA, 2007). Por sua estreita relação com a Feira de Caruaru e relevância cultural, o lugar foi inserido como uma das localidades do Inventário Nacional de Referências Culturais (INRC) da referida feira (IPHAN, 2006), havendo, recentemente, proposta específica de seu registro como patrimônio cultural imaterial do Brasil.

A primeira geração de artesãos-seguidores de Vitalino, hoje com mais de 70 anos, conseguiu transmitir o ofício para parte significativa de seus filhos e filhas. O mesmo não se percebe na geração atual. Em síntese, nossa problematização se volta para uma das transformações que a comunidade vem vivenciando no século XXI, em particular os rumos tomados pela geração que tem se desengajado do ofício de artesão. Em termos mais específicos, volta-se para as demandas disposicionais que precisam ou anseiam atender quando se distanciam daquela ocupação e tomam outros rumos laborais.

Inspirado em aspectos da sociologia de Pierre Bourdieu $(1989,2007)$ e de Bernard Lahire $(2006,2010,2015)$, e compreendendo que a noção de habitus (disposições) serve como instrumento teórico pertinente para suportar análises acerca de práticas socioculturais e econômicas localizadas (VANDENBERGHE, 2016; WACQUANT, 2017), este trabalho é soerguido a partir das seguintes questões: como vem sendo possível o desengajamento dessa nova geração do trabalho artesão na comunidade do Alto do Moura no século XXI? Para quais rumos aponta?

Para atender ao objetivo de analisar as principais condições e os modos de desengajamento da nova geração da comunidade artesã do Alto do Moura, após esta introdução, recupera-se como aporte teórico a sociologia bourdieusiana, em particular a 
noção de habitus (disposições) e a sua atualização crítica por Bernard Lahire. Na terceira seção, apresenta-se a estratégia e os procedimentos metodológicos utilizados. Na quarta seção, o material empírico foi ordenado e analisado. E, nas considerações finais, expomos um olhar para o trabalho fora da condição artesã.

\section{A BUSCA PELO SENTIDO DAS AÇÕES EM CONTEXTO ARTESÃO}

A sociologia bourdieusiana vem se mostrando útil como ferramental teórico a investigações que envolvem pessoas, trabalho e negócios no agreste pernambucano nos últimos anos (SÁ, 2018, 2019; FREIRE, 2016, 2019). Tal corrente e a atualização crítica de Bernard Lahire proporcionam um avanço na elaboração de interpretações sobre os sentidos das ações humanas. $O$ elemento conceitual que mais une as principais obras de Bourdieu (2007) e Lahire (2006) é a noção de habitus. Acreditamos que "para Bourdieu a noção é, em primeiro lugar e acima de tudo, um modo estenográfico de designar uma postura de investigação" (WACQUANT, 2017, p. 216).

Embora nos últimos anos a dimensão contextual tenha sido enfatizada no trabalho de Lahire $(2010,2015)$, tal abordagem foi inicialmente denominada de sociologia disposicionalista da ação (LAHIRE, 2003), uma vez que destaca o núcleo disposicional da noção de habitus enquanto patrimônio ou conjunto de disposições (em linhas gerais, modos de pensar, agir e sentir que governam a ação humana sob os diversos constrangimentos sociais). Para Vandenberghe (2016, p. 29), a sociologia disposicional de Lahire "é tão bourdieusiana de cima a baixo que ele bem poderia ser considerado o sucessor heterodoxo do mestre (sendo Loïc Wacquant o sucessor oficial)". Apesar de tais diferenças, é possível aproximarmos as concepções de Bourdieu-Wacquant e Lahire quando atentamos para as limitações da noção de habitus.

Wacquant (2017, p. 215-216) nos esclarece que "o habitus não é necessariamente coerente e unificado mas revela graus variados de integração e tensão dependendo da compatibilidade e do caráter das situações sociais", e, ainda, que "opera como uma mola que necessita de um gatilho externo e não pode, portanto, ser considerado isoladamente dos mundos sociais particulares". Para ele, há tensões, incoerências e incompatibilidades entre habitus, situações e localismos que ofertam "gatilhos externos" que constrangem determinadas disposições e estimulam outras (a competência para a concentração ou a capacidade de descontração, por exemplo).

Aos nossos olhos, é por meio de tais tensionamentos que podem ser observadas mudanças no patrimônio disposicional herdado e partilhado por membros da nova geração de uma comunidade, como a do Alto do Moura, que se projetam para rumos ocupacionais distintos do artesanato. Ou seja, há novas demandas de (des)incorporação de disposições, e membros da nova geração têm apresentado respostas distintas.

No âmbito dos estudos organizacionais nacionais, Faria e Silva (2017, p. 128) realizaram levantamento no qual se apontou que o "reduzido número de artigos em dez anos no Brasil reforça o potencial da temática do artesanato em oferecer frutos diversos ao campo". Muito embora haja estudos que salientam questões inerentes à dinâmica de negócios e suas demandas à classe artesã, que versam sobre questões de gênero, empreendedorismo, profissionalização, novas formas de organização do trabalho artesanal, entre outros temas e abordagens (VERGARA e SILVA, 2007; MARQUESAN e FIGUEIREDO, 2014; FIGUEIREDO, MELO, MATOS et al., 2015), não encontramos em tal literatura um contexto artesão problematizado nos termos das transformações socioculturais e econômicas que conformam suas novas gerações, afetam seus rumos ocupacionais e até mesmo colocam em risco a continuidade da atividade.

Ainda seria válido salientar que Lahire (2015, p. 1393) advoga por uma metodologia capaz de "contextualizar o presente e o passado dos investigados", e faz alertas que apontam para o forte peso da socialização familiar e a origem social em diversos outros comportamentos. Atento a isso, o autor vem assimilando progressivamente a dimensão contextual ao seu projeto disposicionalista original (NOGUEIRA, 2016).

No caso da comunidade artesã em estudo, por um lado, como a infância na maioria das famílias artesãs é vivida em meio às atividades comuns a uma casa-oficina, não é difícil imaginar que é nesse cotidiano híbrido que se dá a socialização primária dos filhos de tais famílias, e como tais heranças disposicionais são partilhadas com as gerações seguintes. Por outro lado, a projeção da nova geração no sentido de outros contextos de ação, associada a motivações relacionadas ao trabalho, impõe um desafio de adaptação (em maior ou menor grau, a depender da diferença ou semelhança de tal novo contexto ao da casaoficina) a cada um que faz tal trajetória. 
Aos nossos olhos, estamos diante de uma situação de tensão entre patrimônio herdado e novos contextos de ação para os quais os indivíduos que se desengajam do artesanato se projetam. Ao longo da investigação teórico-empírica nos foi possível identificar dois tensionamentos decisivos ao fenômeno do desengajamento: primeiro, aspectos que funcionam como "gatilhos externos" ao desejo, à propensão, à autodeterminação a buscar outra ocupação ou profissão; segundo, o vislumbre e o acesso a rumos alternativos, que podem ter suas raízes em "disposições para crer" (LAHIRE, 2006), ou seja, horizontes de futuro que não estavam tão presentes ou se mostravam pouco viáveis para as gerações anteriores.

\section{ESTRATÉGIA METODOLÓGICA}

Esta pesquisa é qualitativa do tipo descritiva-exploratória. Descritiva pois enfoca a descoberta e a análise de fenômenos procurando descrevê-los e interpretá-los de forma detalhada e exploratória porque visa proporcionar maior familiaridade com o problema e torná-lo mais explícito (RICHARDSON, 1989; FLICK, 2008). Está inserida em um estudo maior no qual uma série de frentes foi aberta para explorar assuntos relacionados principalmente ao artesanato, à comunidade artesã e ao Alto do Moura.

Para aprofundar o tema desengajamento, foram realizadas oito entrevistas semiestruturadas com membros da nova geração (NGE) que trabalham em outra atividade, tendo parte deles estado vinculada aos diversos tipos de produção artesanal local. Em contraponto, foi realizado um grupo focal com seis membros da comunidade que faziam parte da nova geração e continuavam no artesanato. Tanto os sujeitos entrevistados como os participantes do grupo focal foram selecionados de acordo com uma declaração de pertencimento à comunidade, em razão das diferenças e semelhanças (tipicidade), bem como por acessibilidade e não pertencimento a uma mesma família.

Além disso, buscamos trechos que tratavam do assunto desengajamento da nova geração nas observações diretas registradas em notas de campo, entrevistas e grupos focais realizados no âmbito de pesquisa maior, e que também serviram de subsídio para a análise neste trabalho, a saber: entrevistas com vinte artesãos-proprietários de lojas-oficinas (ART), onze proprietários de outros negócios na comunidade (PRO) e cinco formadores de opinião (FOR). E mais dois grupos focais: um com a diretoria da Associação dos Artesãos em Barro e Moradores do Alto do Moura (Abmam) e outro com o Grupo Flor do Barro, formado somente por mulheres artesãs.

Foram elaborados roteiros semiestruturados tanto para as entrevistas como para os grupos focais. 0 roteiro de entrevista com a nova geração foi dividido em três eixos: 1) atividades prévias e atual do entrevistado; 2) razões do não engajamento; e 3) horizontes de futuro.

As pessoas que aqui chamamos de nova geração fazem parte da terceira geração de artesãos do Alto do Moura, ou seja, são os netos da primeira geração formada por Mestre Vitalino e seus contemporâneos, e têm entre 26 e 40 anos.

Como técnica de análise foi adotada a análise temática do conteúdo das entrevistas, grupos focais e notas de campo. Foram selecionados os trechos de fala mais significativos referentes ao desengajamento da nova geração, associados a códigos atribuídos aos temas da estrutura e, de posse dessa seleção, voltamo-nos à discussão do conteúdo.

\section{O DESENGAJAMENTO EM ANÁLISE}

A seguir, o argumento articulado nesta seção foi orientado por três noções: a) gatilhos contextuais (aspectos presentes na contemporaneidade que provocaram ou possibilitaram que a nova geração desejasse efetivamente deixar ou secundarizar a atividade artesã); b) novos rumos (outras ocupações ou profissões buscadas por membros da nova geração); e, perpassando a análise de ambos elementos anteriores, c) as demandas disposicionais (necessidades de mudança nos modos de ser, pensar e agir, incorporadas por aqueles que se projetaram para outro ambiente de trabalho mais ou menos diferente do artesão). 


\section{Gatilhos contextuais}

\section{A dificuldade de transmissão geracional e o seu contexto no século XXI}

Muito embora o Alto do Moura esteja bastante vinculado ao artesanato em barro, é possível observar que, quando falamos do artesanato figurativo, hoje estaríamos diante de uma geração para a qual começa a se observar falta de interesse ou identificação com esse trabalho: "hoje muitos estão... não é perdendo o amor pelo barro, mas tão procurando outras coisas, tenho uma prima que estudou, é professora e já trabalha, outros estão em fábricas, outros foram pra o comércio, e a gente tá perdendo isso" (PRO), "as pessoas jovens não têm mais esse incentivo de aprender, procuram outras áreas" (NGE).

Situações nas quais os mais jovens estariam mais propensos a admirar e buscar ocupações ou profissões associadas à ideia de "moderno", à visão de mundo com a qual desejam se identificar, têm se evidenciado na comunidade: "mesmo tendo jovens fazendo, o artesanato é considerado coisa antiga. Então, tem essas duas coisas, ao mesmo tempo em que eles têm essa dificuldade de formar novas pessoas para ir tocando isso adiante" (FOR).

A atividade artesã pode simbolizar uma espécie de "contracultura" (REES, 1997, p. 130 apud FIGUEIREDO e MARQUESAN, 2014), sobretudo quando a produção ou busca de itens artesanais é um movimento consciente e um tanto dissidente dos padrões capitalistas (FIGUEIREDO e MARQUESAN, 2014). Afinal, o artesanato tende a se contrapor a generalizações, requer tempo, desconexão da ligeireza do modelo industrial (BEZERRA, 2007) e, por extensão, poder-se-ia dizer, do estilo de vida pósmoderno e do mundo globalizado. Nesse contexto, a proximidade com a tecnologia foi apontada por parte dos entrevistados como fundamental ao desengajamento. A comunidade percebe que as crianças têm cada dia mais acesso e se mostram mais interessadas e atraídas por seus artefatos: "você não vê mais nenhum jovem querendo aprender [artesanato] não... Eu tenho um sobrinho lá que boto pra me ajudar, não trabalha dez minutos não, só quer internet" (Grupo focal NGE).

Em meio aos avanços tecnológicos do século XXI, é importante pontuar que as famílias ainda têm papel fundamental no devir da atividade. A transmissão geracional no âmbito familiar mostra-se essencial para compreender como, ao redor do mundo, ainda existem núcleos comunitários responsáveis por salvaguardar o legado do artesanato (ALVARADO, CUENTAS e FERNÁNDEZ, 2016), pautados em um tipo de aprendizagem que começa na socialização primária e que envolve o desenvolvimento de responsabilidade, cooperação e participação (LOPEZ e BIZUET, 2019).

No caso do Alto do Moura, face à dificuldade de dar continuidade à atividade, alguns esforços de resistência têm emergido de fora do âmbito familiar, como aqueles levados adiante pelo grupo "Flor do Barro", que apresenta, entre outros objetivos, o anseio de manter viva a tradição do artesanato na comunidade: "o grupo quer que continue, que não pare, porque a maioria dos filhos dos artesãos não quer mais e a gente queria, assim, que pelo menos conciliasse [com outra atividade]".

\section{O declínio do valor simbólico (reconhecimento) do artesanato e o incentivo insuficiente (apoio do poder público e órgãos de fomento)}

Outros fatores têm feito com que a tendência de não considerar o artesanato uma alternativa válida de ocupação e de fonte de renda se fortaleça na nova geração. Muito embora iniciativas tanto pontuais como sistemáticas da parte do poder público municipal e estadual possam ser observadas, para muitos "o Alto do Moura infelizmente não é valorizado por ter um nome conhecido no Brasil e fora do Brasil, nem é valorizado pelo pessoal de Caruaru, nem pela prefeitura, aí não tem recursos, não tem nada que ajude" (NGE).

A referida desvalorização pode também ser associada, em tal medida, a uma certa encruzilhada conceitual inerente à própria atividade, ora vinculada a um tipo de produção material exposto ao reconhecimento público e passível de comercialização (objetos duráveis, dotados de utilidade e sentido intrínsecos), ora referenciada como um saber vivencial, recolhido ao domínio privado do indivíduo, tendo como foco o valor da tradição. O fato é que, ao guardar estreita semelhança com um tipo de produção "pré-capitalista", pouca ou nenhuma mecanização tecnológica, a atividade apresenta baixo grau de importância na atual configuração econômica, o que fica expresso no fato de as propostas desenvolvimentistas não atribuírem à manufatura forte impacto sobre o desenvolvimento das economias nacionais (FIGUEIREDO, MELO, MATOS et al., 2015).

Tanto em Bezerra (2007) como em Keller (2015) observam-se exemplos de como o poder público e os órgãos de fomento (como o Serviço Brasileiro de Apoio às Micro e Pequenas Empresas - Sebrae) podem intervir de modo a fomentar articulações cooperativistas, promover certa modernização do fazer artesanal, se é que podemos assim dizer, e, por conseguinte, melhorar 
sua rentabilidade para comunidades artesãs. Ressalva-se, no entanto, que mesmo visando preservar e valorizar o artesanato, muitas dessas intervenções governamentais falham no reconhecimento e provimento das necessidades de trabalhadores e de saberes locais quando reproduzem políticas top-down ou instauram o apoio a uns e o abandono a outros (SCRASE, 2003). Conforme se instaura tal desigualdade no olhar do poder público, emerge o desinteresse, conforme justificou uma entrevistada: "eu via que só tinha futuro pra quem compra e revende pra outras pessoas, porque aqui não é tão valorizado como era pra ser, nem os filhos de Vitalino, que foi o fundador do Alto do Moura, tão recebendo valor nesse trabalho, que era pra ser bem mais valorizado" (NGE).

Para Marquesan e Figueiredo (2014), intervenções realizadas por órgãos de fomento como o Sebrae têm por objetivo transformar a produção artesanal brasileira em uma grande geradora de emprego e renda, atrelada aos circuitos de consumo internacional ou à atividade turística. Entretanto, em propostas que fundamentam intervenções desse tipo, é notório o discurso de ressignificação do artesanato e da identidade do artesão por meio do enaltecimento da ação empreendedora e da ênfase sobre a gestão, que usualmente implicam a necessidade premente de impor ao trabalho artesanal os padrões de competitividade inerentes à economia capitalista. Sendo que os novos empreendedores-artesãos têm, nessa ressignificação da sua atividade, a aparência de uma inserção social que não chega a se concretizar de fato.

Quanto ao apoio do poder público e de órgãos de fomento, nosso argumento sobre desengajamento vem, pois, a complementar os achados desta pesquisa: para os artesãos que ainda não se desengajaram plenamente e que se mantêm inseridos (a maioria informalmente) no mundo produtivo do trabalho artesão, sinalizam-se fortes aspectos inerentes a um negócio tipicamente periférico.

\section{A busca de segurança ou estabilidade por meio de outra profissão e/ou dos estudos}

Os entrevistados também relataram que o negócio do artesanato, por ser uma atividade em que muitas vezes atuam por conta própria, apresenta significativa instabilidade financeira. Nesse aspecto, é importante mencionar a elevada informalidade no setor. Enquanto há milhões de artesãos em atividade no país, o Sistema de Informações Cadastrais do Artesanato Brasileiro (Sicab) conta com número bem inferior de artesãos e trabalhadores manuais cadastrados (LORÊTO, DOURADO e SILVA, 2015).

Conforme descrito a seguir, os depoentes se sentem divididos entre a liberdade e a tranquilidade proporcionada pelo trabalho artesanal e o persistente desejo de estabilidade financeira que acreditam poder ser proporcionada por ocupações formalizadas: "As vendas nos últimos dez anos vêm caindo, por isso precisamos de algum incentivo para trazer os mais novos, porque está ficando mais o pessoal de idade, os jovens estão querendo emprego, segurança, né, mas a gente quer que eles aprendam também a fazer" (ART); "O que tem de melhor na atividade do artesanato é a calmaria... e o que há de pior é a instabilidade financeira, você tem hoje, mas não sabe se tem amanhã" (NGE).

Outra forma de buscar uma maior segurança e estabilidade é por meio dos estudos, pois na região o acesso à educação se tornou mais viável neste século: "hoje tem muito curso, tá tudo mais acessível, pra ter um emprego melhor, pra estudar melhor, tem o IFPE [Instituto Federal de Pernambuco], que é aqui bem pertinho, tem muita coisa que ajuda pra você ter uma boa vida no futuro, tudo isso vai tirando o foco do artesanato" (NGE).

O estímulo advindo dos familiares é adicionado às recentes facilidades de acesso à educação técnica ou superior no município, não gozadas por gerações anteriores. ${ }_{1}$ Este último é percebido como elemento marcante para que a nova geração esteja, em parte, direcionando sua motivação para o estudo formal como meio para alcançar postos de trabalho qualificados. Assim, é comum ouvir relatos do tipo: "se a pessoa tem um filho procura investir no estudo dele, para ele crescer, porque no barro tá muito difícil agora para se manter" (Grupo Focal NGE); "Eu quero que eles aprendam a fazer a peça que o pai deles faz, mas

\footnotetext{
${ }^{1} \mathrm{O}$ dispositivo constitucional indicador de necessidade de interiorização de universidades e institutos técnico-profissionalizantes, apontado na Carta de 1988, desapareceu em 1997, na mesma manobra parlamentar de caráter neoliberal que proibiu a expansão dos cursos técnicos federais. A proibição legal para a criação de escolas de educação profissional e tecnológica ruiu, entretanto, nos anos seguintes (BRASIL, 2010a). A ampliação de oportunidades de acesso ao ensino superior tornou-se decorrente, principalmente, da política do Ministério da Educação (MEC) de interiorização do ensino superior, a partir de 2003, e do programa de Apoio a Planos de Reestruturação e Expansão das Universidades Federais (REUNI), em vigor desde 2007. A instalação do campus da Universidade Federal de Pernambuco (UFPE), em 2006, em Caruaru, é fruto desse processo. Adicionalmente, a instalação dos campi da Universidade de Pernambuco (UPE), em 2007, e do IFPE, em 2010, vieram a fomentar tal quadro de inserção de cada dia mais jovens no ensino técnico e superior, do município e de cidades circunvizinhas. Isso sem falar da ampliação da oferta, da redução de preços e das possibilidades de financiamento do mercado do ensino técnico e superior privado.
} 
que eles sejam artesãos não, eu quero alguma coisa melhor pros meus filhos... Quero que eles estudem, façam faculdade e escolham o que eles querem fazer entendeu?" (ART).

É interessante ressalvar que, em outros contextos, artesãos que seguem adiante nos estudos conseguem se destacar e se manter na atividade artesanal. No México, por exemplo, o nível de escolaridade é um aspecto que influencia no negócio do artesanato. Os artesãos com graduação ou profissionalizados utilizam desenhos e técnicas mais sofisticadas, vendem seu trabalho a preços mais altos em lojas de grife ou galerias chiques e alcançaram um melhor padrão de vida; enquanto que os artesãos com nível básico de escolaridade vendem suas peças a preços baixos em lojas de artesanato ou para intermediários (SÁNCHEZ-MEDINA, 2018). No caso do Alto do Moura, entretanto, aqueles que obtêm maior escolaridade tendem a deixar a atividade artesanal e seguir novos rumos.

\section{A dificuldade para geração de renda}

Este é um dos gatilhos que mais fortemente têm contribuído para o desengajamento da nova geração na atividade do artesanato: "dá pra vender uma coisinha, mas não dá muito pra suprir; por exemplo, você vende sempre, mas não vende o tanto que dá pra se manter em um mês... é nesse sentido" (NGE). Além da dificuldade de obtenção de maiores faturamentos nas vendas, a concorrência predatória de preços no Alto do Moura contribui para que a nova geração não consiga obter o mínimo necessário para se manter com qualidade de vida. "Do jeito que tá, acho que ninguém quer mais começar a trabalhar com artesanato não, porque, veja, eu tenho meus fregueses, se eu tinha uma quantidade, hoje eu tenho metade deles, e eu sou velho no artesanato, imagine pra quem for começar agora" (ART).

Avalia-se que tal quadro não é uma especificidade da comunidade estudada, mas sim recorrente em outros contextos periféricos. $\mathrm{Na}$ África do Sul, o artesanato tem seu crescimento limitado devido ao baixo poder de compra dos consumidores finais - a maioria dos negócios é de natureza sobrevivencialista e sazonal, estando intimamente ligada ao turismo (MAKHITHA, 2016). $\mathrm{Na}$ Colômbia, muitos artesãos têm dificuldades para acessar fontes de financiamento e baixa capacidade de negociação com os comerciantes intermediários, chegando a vender seus produtos por valores que não pagam sequer seu dia de trabalho (ALVARADO, CUENTAS e FERNÁNDEZ, 2016). No México, outros enfrentam a escassez na comercialização e a queda nos preços, principalmente devido à concorrência com produtos chineses e novos requisitos impostos pelo governo (SÁNCHEZ-MEDINA, 2018). Tais problemas explicam por que muitos artesãos fabricam em série para sobreviver (VERGARA e SILVA, 2007). No Alto do Moura não é diferente.

\section{Novos rumos e demandas disposicionais}

Os rumos seguintes não têm um caráter linear, mas apenas registram um recorte de trajetórias específicas. Entretanto, é possível apontar por meio das análises que, para cada um deles, percebe-se a necessidade de atendimento a demandas disposicionais mais ou menos diferentes entre si.

\section{Da condição artesã para o negócio próprio na comunidade}

É diante do declínio do valor simbólico e da dificuldade de geração de renda no artesanato que têm surgido variados tipos de negócios no Alto do Moura, tais como lanchonete, mercadinho, salão de beleza etc. Em parte, tais negócios são, sobretudo, de membros da nova geração: "Meu primo mesmo fez um curso e montou esse negócio aí, porque terminou os estudos, não quis trabalhar com o barro por não ter futuro, teve essa ideia e hoje graças a Deus deu certo pra ele" (PRO).

Uma vez projetados para um negócio próprio, alguns membros dessa nova geração ainda se mantêm no artesanato, mas como uma atividade complementar, muitas vezes por vinculação afetiva ao ofício, ou pela familiaridade com esse tipo de ocupação. Entretanto, afirmam que outro tipo de negócio "dá menos trabalho e é melhor financeiramente" (NGE).

Alguns depoimentos também trouxeram à tona as dificuldades enfrentadas por aqueles que, de alguma forma, "se arriscam" a não se tornar artesão em uma comunidade como a do Alto do Moura:

O neto de Vitalino hoje, um cara com um [sobre]nome desse, ele montou um mercado, e o ateliê dele é uma mesinha lá atrás, e isso me deixou muito triste realmente, e agora vai inclusive fechar o mercado, não deu certo, acho que saturou mesmo. A facilidade né, o shopping e tal, a gente sabe né, ônibus regular, tudo isso facilita com que eles tenham o acesso mais fácil até a cidade (FOR). 
Em termos gerais, trocar o artesanato por um negócio de outra natureza na própria comunidade tende a demandar a incorporação de uma visão de mundo e de negócios mais próxima das práticas de mercado convencional, resiliência para desenvolver mais atividades que não requerem a vinculação afetiva ou mesmo a concentração individual (como no artesanato), e que se adquira ou reative (para aquele que antes teve tal tipo de experiência) competências em gestão de um negócio periférico diferente da casa-loja-oficina.

Muito embora quem faça o deslocamento da condição artesã para a de proprietário de outro negócio na comunidade continue trabalhando no mesmo espaço social, é possível indicar mudanças associadas à desincorporação de disposições associadas ao habitus artesão para a incorporação de outras características ao habitus comerciante. Apesar de próximos em termos de práticas e visões de mundo que engendram, tal deslocamento tende a implicar mudanças nas qualidades morais, nos sentimentos, desejos, enfim, na conduta dos indivíduos (WACQUANT, 2017).

\section{Da condição artesã para a atividade formal não especializada}

O artesanato pode ser compreendido como expressão genuína de uma cultura local, expressão que marca, por meio de técnica específica, o fazer, o conhecimento tácito acumulado por gerações, demarcação original de uma territorialidade (CASTILHO, DORSA, SANTOS et al., 2017). A migração para trabalhar no centro da cidade ou em outros locais denota, por si só, um afastamento do contexto territorial mas também social da comunidade, contribuindo para o processo de desengajamento.

O rumo para atividades formais não especializadas leva a nova geração a trabalhar com carteira assinada em empresas da cidade, no Distrito Industrial (localizado no perímetro geográfico do Alto do Moura), ou mesmo no próprio núcleo habitacional do bairro. O principal gatilho associado a esses casos é a busca da estabilidade financeira, sobretudo porque "o jovem se sente inseguro no artesanato e acha melhor o emprego" (PRO), ou ainda porque "nem todo mundo que trabalha com o barro consegue sobreviver bem, tem uma casa boa, um carro, uma moto, não são todos, então muitos viram a oportunidade de ter um salário fixo e foram embora do artesanato" (NGE).

É recorrente a menção, por parte de alguns entrevistados, ao fato de que a migração para o trabalho em uma atividade formal não especializada tem se mostrado uma tendência até mesmo para a nova geração das famílias mais tradicionais, pois "vai chegar um tempo que os filhos e netos das famílias tradicionais vão começar a ir para as fábricas e firmas; na verdade, isso já está acontecendo - não que isso seja errado, mas não deveria deixar de fazer aquele trabalho tão importante que deu início nos primórdios, isso é muito sério" (ART).

O mesmo respondente, ao citar também que um dos netos de Mestre Vitalino "escolheu outro modo de viver e foi trabalhar no Distrito Industrial", pontua outro deslocamento (do habitus artesão) percebido entre os membros da própria comunidade: "tá criando outro Alto do Moura sem a gente perceber, tem outra rotina, porque quem trabalha no Distrito Industrial também sai mais cedo, então vai criando uma cultura, embora o lugar seja pequeno, mas vai criando culturas" (FOR).

Entre as demandas disposicionais necessárias para seguir nesse rumo, podemos inferir que a nova geração é levada a desenvolver a obediência hierárquica à autoridade formal (acatar decisões de um superior); a adaptação ao deslocamento e ao trabalho em outros espaços diferentes da casa-oficina; e o cumprimento de horário determinado por outrem, diferentemente do artesanato, onde geralmente o próprio artesão faz seu horário.

Em relação ao rumo anterior, aqui é possível conjecturar mudança mais significativa nas disposições daqueles que o seguem, uma vez que o cotidiano laboral, na ampla maioria dos casos, passa a ser outro território. Tais mudanças aqui apontariam para o atendimento a demandas associadas a um tipo de habitus trabalhador (não especializado), moldado em contexto empresarial-industrial, em detrimento do patrimônio disposicional recebido como herança comunitária.

\section{Da condição artesã para a atividade técnico-profissional (com diploma técnico ou universitário)}

Em termos gerais, dispondo de maiores possibilidades de acesso à educação pós-escolar que a geração anterior, muitos membros da nova geração têm buscado, por meio do estudo, inserção em frações mais qualificadas do mercado de trabalho. Uma de nossas depoentes, que foi a primeira da sua família a concluir um curso superior (em pedagogia), disse que, ao fazê-lo, "quebrou um paradigma, um roteiro que vinha sendo seguido" (NGE). Quando comparou sua atual profissão com o trabalho artesão dos pais, assim comentou: "Às vezes eu sinto falta, sabe, porque é uma terapia. Eu fico comparando o meu trabalho com o de mainha e painho e vejo a calmaria que é [...] dá uma certa inveja" (NGE). 
Uma segunda entrevistada, além de já possuir um curso técnico de enfermagem, cursava, à época, direito. Logo que terminou o curso técnico, conseguiu trabalho num hospital, mas sobre o seu futuro falou: "eu gosto, adoro o que faço, mas não é uma coisa que eu quero pra o resto da vida" (NGE). Assim, projetou que quando terminasse sua faculdade iria estudar para concurso e continuar no seu emprego até conseguir algo melhor, mais ou menos repetindo como fez quando trabalhava no artesanato, pois foi assim que conseguiu custear sua primeira formação.

Como gatilhos associados a tal rumo, é possível apontar: a desvalorização simbólica da atividade artesã, o pouco incentivo do poder público percebido pela comunidade e, principalmente, o estímulo dos pais para que, por meio do estudo, e buscasse uma profissão, rumo visto como melhor que seguir no artesanato.

Assim como constatado por Martins (2019), observam-se indícios de um baixo nível de escolaridade na comunidade do Alto do Moura. Boa parte dos artesãos de gerações anteriores é analfabeta ou não concluiu o ensino fundamental. Porém, ao contrário do observado pelo mesmo autor, nos achados de nossa pesquisa, constata-se que, na medida em que as novas gerações vão tendo acesso a oportunidades educacionais, em ensino superior ou técnico, o conhecimento formal passa a se configurar, ao menos para esses jovens, como um elemento moral valorizado.

Os relatos colhidos indicaram demandas específicas, como trabalhar noutro ritmo mais acelerado do que no trabalho artesanal, e praticar poupança para investir em novas etapas formativas. Ademais, podemos inferir que, para seguir adiante no sentido da profissão especializada, jovens como as nossas entrevistadas precisaram atender a demandas disposicionais como a incorporação de disciplina de estudo, a capacidade de abstração crítico-reflexiva e o cumprimento de rotinas acadêmicas.

Adquirir o espírito acadêmico exigido pelo engajamento em formação técnica ou universitária demanda uma conversão disposicional que tanto pode repercutir nas práticas socioculturais do indivíduo quanto nos horizontes de futuro. Ao mesmo tempo, tal deslocamento permite a "aquisição das disposições de conduta que capacitam os agentes a operar em uma economia capitalista” (PETERS, 2017, p. 283) na condição de profissional liberal, por exemplo.

\section{Da condição artesã para o trabalho informal (precário ou intermitente)}

Em uma última análise, há também aqueles que se ocupam com trabalho informal esporádico. Em muitos desses casos, observamos que tais membros da nova geração seguem em paralelo fazendo peças de barro. Entretanto, a necessidade de melhoria na renda ou mesmo o melhor retorno obtido com outras atividades faz com que eles se mostrem sucetíveis a tal rumo:

Eu trabalhei com outros estilos variados [...] mas no momento o que tá saindo pra mim é isso aí e não tá muito bom o comércio não, entendeu? A verdade é tanta que eu procuro fazer outras atividades, mexo com eletricidade, trabalho na feira também, às vezes faço trabalho de garçom, churrasqueiro, essas coisas, entendeu? A gente tem que fazer o que no momento tá saindo para a pessoa, porque, se for esperar, não dá para sobreviver [do artesanato], a palavra certa é essa! Para se manter só no barro hoje em dia tá muito difícil, [...] a maioria quer sair, arrumar um emprego fichado (Grupo Focal NGE).

O desejo de estabilidade por meio de um emprego formal mostra-se mais uma vez presente. $O$ feito de conseguir um trabalho com carteira assinada, no entanto, não está ao alcance de todos, principalmente quando observado o quadro econômico nacional-regional-local. Para aqueles que, como o nosso depoente, precisam recorrer a outras ocupações não formalizadas e intermitentes, é preciso se ajustar no sentido do atendimento das demandas disposicionais que tal rumo pode engendrar. Ou seja, desenvolver aptidões e competências para sobreviver num quadro de insegurança financeira, ampliar a resistência física para trabalho braçal ou, ainda, em larga medida, mostrar-se versátil para incorporar e desincorporar as demandas específicas relacionadas com cada contexto de ação e atividade a ser nele desempenhada. Afinal, tais demandas podem variar significativamente se, por exemplo, num mês se está trabalhando como servente (em obras), noutro como garçom (em bares ou restaurantes populares), ou, ainda, como trabalhador-diarista na feira.

Rumo de maior risco, caso não consiga desenvolver a capacidade de sobreviver de biscates, ou mesmo em quadros contextuais desfavoráveis (que estão além do alcance de suas competências), o indivíduo aqui pode se aproximar da condição da "ralé brasileira", ou seja, "incapaz de atender às demandas de um mercado cada vez mais competitivo [...]. Como [o indivíduo] não encontra emprego no setor produtivo que pressupõe uma relativa alta incorporação de conhecimento técnico ou 'capital cultural', [...] só pode ser [empregado] como mero 'corpo', ou seja, como mero dispêndio de energia muscular" (SOUZA, 2009, p. 23-24). 


\section{CONSIDERAÇÕES FINAIS: UM OLHAR PARA O TRABALHO FORA DA CONDIÇÃO ARTESÃ}

O gatilho "dificuldade de geração de renda" está evidente para todos os rumos analisados. Não fosse apenas pela questão financeira, a busca pela estabilidade de um emprego evidencia o peso da "carteira assinada", que tanto diferencia as atividades formalizadas do artesanato. O declínio do valor simbólico e a dificuldade de transmissão geracional surgem, por sua vez, como fatores atenuantes das mudanças de rumo, sendo o primeiro mais localizado e percebido com mais clareza por parte da própria comunidade e, o segundo como um aspecto não exclusivo daquele lugar.

Aos nossos olhos, a face mais visível dos rumos adotados pela nova geração é o negócio próprio na comunidade. Afinal, além do desengajamento propriamente dito, tais negócios estão sendo responsáveis por criar uma nova paisagem urbana local (hoje repleta de letreiros e conclames aos mais diversos tipos de consumo) e uma lógica própria de oferta de produtos e serviços ao maior contingente de pessoas que passaram a habitar o bairro e seu entorno nos últimos anos.

O confronto do material empírico com o aporte ofertado pela sociologia de Pierre Bourdieu e Bernard Lahire nos possibilita particularmente inferir que, de modo geral, além da propensão para negociação, os que se projetam no sentido do negócio por conta própria carecerão, cada vez mais, de desenvolver competências para a tomada de decisão e outras habilidades referentes à condução de um negócio que não as casas-lojas-oficinas típicas de quem produz e vende peças de barro.

Deixar de ser artesão para ser comerciante também pressupõe, contudo, demandas disposicionais inerentes à conformação de uma nova condição laboral: como ser filho da comunidade artesã do Alto do Moura, ter um negócio por lá, mas não ser artesão? Para os que se consideram membros da comunidade artesã, como agir como dono de negócio de outra natureza? Perguntas como essas poderiam ser respondidas com elementos referentes, por exemplo, à impessoalização da condição laboral, não mais afetiva ou vinculada a um saber repassado de pais para filhos, no seio das famílias, como recorrente no que diz respeito ao ofício artesão.

Talvez a proximidade com o legado de Mestre Vitalino e o interesse externo em conhecer as condições de vida e trabalho daqueles que seguiram na trilha aberta por ele, ao longo da segunda metade do século passado, tenham motivado a segunda geração e possibilitado a configuração de um contexto favorável ao seguimento no artesanato de parte significativa de seus membros. Já em relação à geração tomada como foco deste trabalho, é possível observar uma maior dificuldade contextual para o engajamento na atividade neste século XXI.

Traçar, entretanto, um ponto de chegada ou especular um cenário em que descrevemos o que esperar das novas gerações (não somente daquela para a qual este trabalho se volta, mas também para as futuras) nos parece mais complexo, uma vez que encontramos, em meio às variadas tensões vivenciadas pela comunidade, depoimentos que reforçam tanto a afeição à atividade como o receio de sua extinção. O que mais nos parece consistente é observar os rumos e as demandas disposicionais a eles associadas (anteriormente analisadas) como tendências projetivas e reativas aos gatilhos contextuais - que evidenciam um processo inquestionável, ao menos aos nossos olhos, de desengajamento em curso.

\section{AGRADECIMENTOS}

Agradecemos à Fundação de Amparo à Ciência e Tecnologia de Pernambuco (FACEPE) pelo apoio concedido para a realização da pesquisa (processo: BIC-1142-6.02/17) que deu origem para este artigo. 


\section{REFERÊNCIAS}

ALVARADO, Y. N. R.; CUENTAS, M. M. C.; FERNÁNDEZ, D. L. M. Prácticas del mercado artesanal de la etnia wayú en Riohacha (La Guajira, Colombia)... Pensamiento \& Gestión, n. 41, 2016.

ARAÚJO, D. M. M. João e Maria de Barro: quem são? As loiceiras do Tope, em Viçosa do Ceará. 2006. Dissertação (Mestrado em Antropologia) - Programa de Pós-Graduação em Antropologia, Universidade Federal de Pernambuco, Recife, 2006.

BeZerra, N. X. Cerâmica de Santo Antônio do Potengi... 2007. Dissertação (Mestrado em Antropologia Social) - Universidade Federal do Rio Grande do Norte, Natal, 2007.

BOURDIEU, P. A distinção... São Paulo; Porto Alegre: Edusp; Zouk, 2007.

BOURDIEU, P. O poder simbólico. Lisboa; Rio de Janeiro: Difel; Bertrand Brasil, 1989.

BRASIL. Ministério do Desenvolvimento, Indústria e Comércio Exterior (MDIC). Programa do artesanato brasileiro. Brasília: MDIC, 2013.

BRASIL. Ministério da Educação. Ministro destaca a expansão e a interiorização do ensino. Portal MEC, 7 maio 2010a. Disponível em: <http://portal.mec.gov.br/ultimas-noticias/212-educacao-superior1690610854/15405-ministro-destaca-a-expansao-e-a-interiorizacaodo-ensino>. Acesso em: 21 mar. 2020.

BRASIL. Portaria no 29 de 5 de outubro de 2010. Torna pública a base conceitual do Programa do Artesanato Brasileiro (PAB). Diário Oficial da União, Brasília, DF, no 192, 6 de outubro de 2010, Seção 1, p. 100, 2010b.

CANCLINI, N. As culturas populares no capitalismo. São Paulo: Brasiliense, 1983.

CASTILHO, M. A. et al. Artesanato e saberes locais no contexto do desenvolvimento local. Interações, Campo Grande, v. 18, p. 91-202, n. 3, 2017.

DRAGIN, A. et al. Craft as a Business Development Challenge: Latvian and Serbian Craftsmen's Views. Procedia - Social and Behavioral Sciences, n. 185, p. 76-83, 2015.

FARIA, A. M.; SILVA, A. R. L. Artesanato nos estudos organizacionais: a literatura brasileira de 2006 a 2015. Pensamento Contemporâneo em Administração, v. 11, n. 2, p. 120-135, 2017.

FIGUEIREDO, M. D.; MARQUESAN, F. F. S. Arte, design... Por que isso importa aos estudos organizacionais? Revista Interdisciplinar de Gestão Social, v. 3, n. 3, p. 127-143, 2014.

FIGUEIREDO, M. D.; MELO, A. N.; MATOS, F. R. N.; MACHADO, D. Empreendedorismo feminino no artesanato... RECADM, v. 14, p. $110-123,2015$.

FLICK, U. Uma introdução à pesquisa qualitativa. 3. ed. Porto Alegre: Bookman, 2008.

FREIRE, C. Da Sulanca à fabrica... 2016. Tese (Doutorado em Ciências Sociais) - Universidade Federal de Campina Grande, Campina Grande, 2016.

FREIRE, C. Da condição de trabalhador à condição de empresário... Curitiba: Appris, 2019.
INSTITUTO DO PATRIMÔNIO HISTÓRICO E ARTÍSTICO NACIONAL IPHAN. Dossiê Feira de Caruaru: Inventário Nacional de Referência Cultural. Recife: Iphan, 20 set. 2006.

KELLER, P. O artesão e a economia do artesanato na sociedade contemporânea. Política \& Trabalho, n. 41, p. 323-347, 2015.

LAHIRE, B. A cultura dos indivíduos. Porto Alegre: Artmed, 2006.

LAHIRE, B. A fabricação social dos indivíduos. Educação e Pesquisa, v. 41, n. especial, p. 1393-1404, 2015.

LAHIRE, B. O homem plural. Lisboa: Instituto Piaget, 2003.

LAHIRE, B. Por uma sociologia disposicionalista e contextualista da ação. In: JUNQUEIRA, L. (org.). Cultura e classes sociais na perspectiva disposicionalista. Recife: Editora UFPE, 2010. p. 17-36.

LOPEZ, S. L.; BIZUET, A. I. Tejido y vida cotidiana: "El cuerpo manda". Discurso sobre trabajo y corporeidad entre las artesanas expertas de San Juan Chamula. LiminaR, v. 17, n. 2, p. 131-147, 2019.

LORÊTO, M. S. S.; DOURADO, D. C. P.; SILVA, I. P. "Do barro ao forno": analisando para onde as práticas discursivas sobre políticas públicas nacionais de artesanato apontam. In: CONGRESSO BRASILEIRO DE ESTUDOS ORGANIZACIONAIS, 3., 2015, Vitória. Anais ... Vitória, ES: UFES, 2015.

MAKHITHA, K. M. Do small craft businesses need strategic marketing to survive? Investment Management and Financial Innovations, v. 13, n. 2-2, p. 399-404, 2016.

MARQUESAN, F. F. S.; FIGUEIREDO, M. D. De artesão a empreendedor... RAM, v. 15, n. 6, Edição Especial, p. 76-97, 2014.

MARTINS, D. F. V. A perspectiva da moral na aprendizagem da prática do artesanato de barro. Revista Interdisciplinar de Gestão Social, v. 8, n. 1, 2019.

NOGUEIRA, C. M. M. Bernard Lahire: contribuições e limites de uma sociologia em escala individual. In: VANDENBERGHE, F.; VÉRAN, J. F. (org.). Além do habitus: teoria social pós-bourdieusiana. Rio de Janeiro: 7Letras, 2016. p. 49-69.

PETERS, G. De volta à Argélia. A encruzilhada etnossociológica de Bourdieu. Tempo social, v. 29, n. 1, p. 275-303, 2017.

RICHARDSON, R. J. Pesquisa social: métodos e técnicas. São Paulo: Atlas, 1989.

SÁ, M. Feirantes: quem são e como administram seus negócios. 3. ed. Recife: Editora UFPE, 2019.

SÁ, M. Filhos das feiras: uma composição do campo de negócios agreste. Recife: Massangana; Fundaj, 2018.

SÁ, M.; SOUSA, J.; SOUZA, D.; SILVA, S.; LEAL, B.; SILVA, T. Seguir ou não no artesanato: modos de fazer, desafios e emergência de outros negócios no Alto do Moura do século 21. In: ENCONTRO DA ASSOCIAÇÃO NACIONAL DE PÓS-GRADUAÇÃO E PESQUISA EM ADMINISTRAÇÃO, 42., Curitiba, 2018. Anais... Curitiba: ANPAD, 2018.

SÁNCHEZ-MEDINA, P. S. La estrategia ambiental en pequeños negocios de artesanía, un ejemplo de medición. Investigación y Ciencia, v. 26, n. 73, p. 74-83, 2018. 
SCRASE, T. J. Precarious production: globalization and artisan labor in the third world. Third World Quaterly, v. 24, n. 3, p. 449-461, 2003.

SILVA, L. P. A disputa da Argila pelos artesãos do Alto do Moura Caruaru-PE. 2007. Dissertação (Mestrado em Geografia) - Universidade Federal de Pernambuco, Recife, 2007.

SOUZA, J. A ralé brasileira: quem é e como vive. Belo Horizonte: Editora UFMG, 2009.
VANDENBERGHE, F. Os pós-bourdieusianos... In: VANDENBERGHE, F.; VÉRAN, J. F. (Orgs.). Além do habitus: teoria social pós-bourdieusiana. Rio de Janeiro: 7Letras, 2016. p. 27-36.

VERGARA, S; SILVA, H. Organizações artesanais: um sistema esquecido na teoria das organizações, Revista Portuguesa e Brasileira de Gestão, v. 6, n. 3, p. 32-38, 2007

WACQUANT, L. Habitus. In: CATANI, A. M. et al. (orgs.). Vocabulário Bourdieu. Belo Horizonte: Editora, 2017. p. 213-217. [Verbete].

Denise Clementino de Souza

ORCID: https://orcid.org/0000-0002-8292-5175

Doutora em Administração pela Universidade Federal de Pernambuco (UFPE); Pesquisadora do Grupo de Estudos e Intervenções do Agreste (GEIA); Professora Adjunta do Núcleo de Gestão, Centro Acadêmico do Agreste da Universidade Federal de Pernambuco (UFPE), Caruaru - PE, Brasil. E-mail: profadenisesouza@gmail.com

Jessica Rani Ferreira de Sousa

ORCID: https://orcid.org/0000-0001-8672-9246

Mestra em Administração pelo Programa de Pós-Graduação em Administração da Universidade Federal de Pernambuco (PROPAD/UFPE); Pesquisadora do Grupo de Estudos e Intervenções do Agreste (GEIA); Professora Substituta no Núcleo de Gestão, Centro Acadêmico do Agreste da Universidade Federal de Pernambuco (UFPE), Caruaru - PE, Brasil. E-mail: jessica_rani@hotmail.com

Marcio Gomes de Sá

ORCID: https://orcid.org/0000-0002-1001-8381

Doutor em Sociologia pela Universidade do Minho (UM); Pesquisador do Grupo de Estudos e Intervenções do Agreste (GEIA); Professor-pesquisador do Departamento de Ciências Sociais, Universidade Federal da Paraíba (UFPB), João Pessoa - PB, Brasil. E-mail: marciodesa@gmail.com

\section{Bárbara Tayna Leal}

ORCID: https://orcid.org/0000-0002-8014-974X

Bacharel em Administração pela Universidade Federal de Pernambuco (UFPE), Caruaru - PE, Brasil. E-mail: lealbarbara18@gmail.com 